2009, a period that was conducted to collect data. Through a quantitative approach, number of fundamental importance to this study, because through their meanings becomes profitable and easy to control. The results show that 13 patients had 40 to 60 years of age and 14 were between 10 and 39 years, 70\% were female and the majority consisted of low-income people and poor literacy. Of the patients, $70 \%$ were paucibacillary and multibacillary remaining $30 \%$. The results indicate that patients with leprosy showed the need for educational interventions to prevent and knowledge of the disease and also actions aimed at planning assistance to leprosy patients were included in these lawsuits nursing care.

\section{P1-316 POPULATION IMPACT AND APPROPRIATENESS OF TREATMENT ACCORDING TO DIFFERENT OSTEOPOROSIS GUIDELINES}

doi:10.1136/jech.2011.142976f.8

G Sanfélix-Gimeno, ${ }^{*}$ I Hurtado, S Peiró, J Sanfélix-Genovés. Centre for public health research, Valencia, Spain

Introduction The aim of this study was to evaluate the impact and appropriateness of treatment according to different osteoporosis guidelines (National Osteoporosis Foundation (NOF), Community of Madrid (CMA) and General Practitioners' Society (SEMERGEN)) in women over 50 years in Spain

Method Cross-sectional study conducted between 2006 and 2007 in Valencia, Spain. An age-stratified population-based random sample of 824 postmenopausal women over 50 answered a questionnaire about risk factors and anti-osteoporotic treatment, and received a lumbar spine and hip densitometry and a spine x-ray. The population impact and the appropriateness of treatment according to each guideline was evaluated.

Results The population of women over 50 who should be treated according to different guidelines would be $15.5 \%$ (95\% CI 14.0 to 19.0) for CMA, $25.4 \%$ (95\% CI 22.4 to 28.3 ) for SEMERGEN and $36.9 \%$ (95\% CI 33.6 to 40.2 ) for NOF. These figures would be translated into 1.3 to 3.2 million women candidates for treatment in the Spanish NHS. Regarding the appropriateness of anti-osteoporotic treatment, $80 \%, 66 \%$ and $52 \%$ of the women treated $(n=181$; $21.9 \%$ ) did not meet CMA, SEMERGEN and NOF criteria to be treated, respectively. Whereas $16 \%, 23 \%$ and $34 \%$ of untreated women ( $\mathrm{n}=643 ; 78.0 \%$ ) should receive treatment according to CMA, SEMERGEN and NOF guidelines.

Conclusions There are huge differences in the population impact of three commonly used guidelines. Appropriateness of anti-osteoporotic treatment was low due to overuse in women without indication and also because of underuse in women with criteria for treatment.

\section{P1-317 INCIDENCE OF SEVERE WORK-RELATED INJURIES AMONG YOUNG ADULT WORKERS IN BRAZIL- ANALYSIS OF COMPENSATION DATA}

doi:10.1136/jech.2011.142976f.9

\footnotetext{
$1,2 \mathrm{~V}$ Santana, ${ }^{* 2} \mathrm{~A}$ Villaveces, ${ }^{2} \mathrm{~K}$ Bangdwala, ${ }^{2} \mathrm{C}$ Runyan, ${ }^{3} \mathrm{P} \mathrm{R}$ Albuquerque-Oliveira. ${ }^{1}$ Federal University of Bahia, Salvador, Bahia, Brazil; ${ }^{2}$ University of North Carolina, Chapel Hill, North Carolina, USA; ${ }^{3}$ Ministry of Social Security, Brasila, Distrito Federal, Brazil
}

Objectives To obtain national estimates of annual cumulative incidence of severe non-fatal injuries using compensation benefits data from the Brazilian National Social Security Institute (INSS), and to describe their socio-demographic distribution among workers under age 25 .

Methods Data are records of health-related compensation benefits from the Ministry of Social Security's Information System of Compensation Benefits (SUB), of the National Institute of Social Security (INSS), recorded in 2006. The only injuries (International classification of diseases, $10^{\text {th }}$ revision, Chapter XIX) considered were those certified by an INSS occupational physician s workrelated for adolescents and young adults between 16 and 24 years of age.

Results A total of 79899 workers 16-24 years old received a compensation benefit for injuries in the study year, and 19439 (24.33\%) were work-related, 16878 (86.8\%) for males and 2,561 for females (13.2\%). The annual cumulative incidence rate of workrelated injuries (ACSWI) was $3.9 \times 1000$ workers, higher among males $(4.6 \times 1000)$ compared to females $(1.3 \times 1000)$. ACSWI was higher in the younger age group (16-19 years), and there was an income gradient with disproportionately elevated risk in the lowest wage quintiles, especially for females in the younger group. Logging, extraction, food/beverage and construction industries have higher work-related risk for adolescents and young adult workers of both sex groups.

Conclusions These findings suggest that the Brazilian labour laws limiting young adult workers in hazardous settings need to be expanded, adding occupations, extractive industries and certain types of work in the food/beverage manufacturing industries for these workers.

\section{P1-318 LATE PRETERM BIRTH AND RISK OF BEHAVIOURAL PROBLEMS AT 4 YEARS OF AGE}

doi:10.1136/jech.2011.142976f.10

${ }^{1}$ I Santos, ${ }^{*}{ }^{1}$ A Matijasevich, ${ }^{1} \mathrm{~A}$ Barros, ${ }^{2} \mathrm{~L}$ Anselmi. ${ }^{1}$ Federal University of Pelotas, Pelotas, Rio Grande do Sul, Brazil, ${ }^{2}$ Federal University of the State of Rio Grande do Sul, Porto Alegre, Brazil

Introduction Preterm births have been associated with behavioural problems later on. This study aimed to investigate whether late preterm (LPT) children (34-36 weeks gestation) are at increased risk of presenting behavioural problems at the age of 4 years old comparatively to full term children (37-42 weeks).

Methods Children from the 2004 Pelotas Birth Cohort were enrolled just after birth and were followed-up at home in several occasions when information on a series of maternal (socioeconomic, demographic, reproductive, and behavioural characteristics, and maternal depression) and child co-variables (intensive care unit hospitalisation at birth, hospitalisations during the first year, breastfeeding duration and bed-sharing) was collected by trained fieldworkers. Estimated gestational age was based on last menstrual period or, when unknown or inconsistent, through the Dubowitz method. Presence of behavioural problems was assessed through application of the Child Behaviour Checklist (CBCL) to the mothers. Adjusted analyses were run through linear regression.

Results There were 4231 livebirths, $14.5 \%$ were preterm newborns, $77 \%$ of whom were LPT. A total of 3411 children were assessed at the age of 4 years (416 LPT and 2995 full term). Mean CBCL rates were higher for LPT than for full term children (36.6 and 34.2, respectively; $p=0.007$ ). After allowing for confounders (family income, maternal and child characteristics) the association was no longer significant $(\beta=0.4 ; \mathrm{SE}=0.9 ; \mathrm{p}=0.635)$. No interaction was observed between LPT and any of the studied co-variables.

Conclusion LPT children present higher rates in CBCL than term children, but the difference relies mainly on lower socioeconomic conditions. 